\title{
Do spirituality and faith make a difference? Report from the Southern European Psycho-Oncology Study Group
}

\author{
LUZIA TRAVADO, PH.D., ${ }^{1}$ LUIGI GRASSI, M.D., ${ }^{2}$ FRANCISCO GIL, PH.D., ${ }^{3}$ \\ CRISTINA MARTINS, PH.D., ${ }^{1}$ CIDÁLIA VENTURA, PH.D., ${ }^{1}$ JOANA BAIRRADAS, PH.D. ${ }^{4}$ AND \\ THE SOUTHERN EUROPEAN PSYCHO-ONCOLOGY STUDY GROUP \\ ${ }^{1}$ Clinical Psychology Unit, Central Lisbon Hospital Center - Hospital S. José, Lisbon, Portugal \\ ${ }^{2}$ Department of Behavior and Communication, Section of Psychiatry, University of Ferrara and Department of Mental \\ Health and General University S. Anna Hospital, Ferrara, Italy \\ ${ }^{3}$ Psycho-Oncology Unit, Hospital Duran i Reynals, Catalan Institute of Oncology, L'Hospitalet, Barcelona, Spain \\ ${ }^{4}$ PsiSaude, Center for Research in Health and Human Development, Lisbon, Portugal
}

(RECEIved March 25, 2010; ACCEPTED April 27, 2010)

\begin{abstract}
Objective: In the last decade, some attention has been given to spirituality and faith and their role in cancer patients' coping. Few data are available about spirituality among cancer patients in Southern European countries, which have a big tradition of spirituality, namely, the Catholic religion. As part of a more general investigation (Southern European Psycho-Oncology Study SEPOS), the aim of this study was to examine the effect of spirituality in molding psychosocial implications in Southern European cancer patients.

Method: A convenience sample of 323 outpatients with a diagnosis of cancer between 6 to 18 months, a good performance status (Karnofsky Performance Status > 80), and no cognitive deficits or central nervous system (CNS) involvement by disease were approached in university and affiliated cancer centers in Italy, Spain, Portugal, and Switzerland (Italian speaking area). Each patient was evaluated for spirituality (Visual Analog Scale 0-10), psychological morbidity (Hospital Anxiety and Depression Scale-HADS), coping strategies (Mini-Mental Adjustment to Cancer - Mini-MAC) and concerns about illness (Cancer Worries Inventory - CWI).

Results. The majority of patients (79.3\%) referred to being supported by their spirituality/ faith throughout their illness. Significant differences were found between the spirituality and non-spirituality groups ( $p \leq 0.01$ ) in terms of education, coping styles, and psychological morbidity. Spirituality was significantly correlated with fighting spirit $(r=-0.27)$, fatalism $(r=0.50)$, and avoidance $(r=0.23)$ coping styles and negatively correlated with education $(r=-0.25)$, depression $(r=-0.22)$ and HAD total $(r=-0.17)$.

Significance of results: Spirituality is frequent among Southern European cancer patients with lower education and seems to play some protective role towards psychological morbidity, specifically depression. Further studies should examine this trend in Southern European cancer patients.
\end{abstract}

KEYWORDS: Spirituality, Cancer coping, Southern Europe Psycho-oncology

Address correspondence and reprint requests to: Luzia Travado, Unidade de Psicologia Clínica, CHLC - Hospital de S. José, Rua José António Serrano,1150-199 Lisboa, Portugal. E-mail: luzia. travado@chlc.min-saude.pt

\section{INTRODUCTION}

In the last decade, some attention has been given to the importance of religion and spirituality and their role in cancer patients' coping and quality of life (Mytko \& Knight, 1999). Spirituality has been 
defined as "personal views and behaviors that express a sense of relatedness to a transcendent dimension or to something greater than the self" (Reed, 1987); religiosity has been defined as "participation in the particular beliefs, rituals and activities of traditional religious systems" (Elkins et al., 1988). Although many authors make a distinction between spirituality, and religiosity, preferring the first, because it is more inclusive and universal (Moberg, 1979; Hiatt, 1986; Reed, 1987; Elkins et al., 1988; Ley \& Corless, 1988), several studies examined the whole concept of spirituality/religiosity, including the patients' faith and the help they receive from their faith, and several scales have been developed to measure the concept of spirituality in a broader sense (Mytko \& Knight, 1999).

A positive influence of spirituality on various dimensions of health whether it be physical health, mental health, or well-being, have been reported (Matthews et al., 1993; Matthews \& Larson, 1995; Fitchett et al., 1996; Larson \& Greenwold-Milano, 1995; Matthews, 1997; Bussing et al., 2005; Canada et al., 2006). Spirituality has also been associated with positive subjective perceptions of health status (St. George \& McNamara, 1984; Broyles \& Drenovsky, 1992), lower levels of depression and psychological distress (Idler, 1987; Williams et al., 1991; Smith et al., 2003), enhanced subjective states of well-being (Ellison, 1991), better coping skills, and better health-related quality of life (Bussing et al., 2005). Also, religious involvement has been considered a predictor of all-cause mortality in which individuals with lower religious involvement were at greater risk of death at follow-up than those more religiously involved (McCullough et al., 2000).

In cancer, considering the potentially life threatening nature of the illness, using religion and spirituality resources may be specifically relevant on how cancer patients cope with their illness and suffering. In this sense, numerous studies have found that religion and spirituality provide effective coping mechanisms for patients as well as for family caregivers (Weaver \& Flannelly, 2004).

Religious and spiritual coping have been also referred to as serving multiple functions in longterm adjustment to cancer such as maintaining selfesteem, providing a sense of meaning and purpose, giving emotional comfort, and providing a sense of hope (Feher \& Maly, 1999; Thune-Boyle et al., 2006). A number of studies have also shown that religiosity and spirituality significantly contribute to psychosocial adjustment to cancer and its treatments (Musick et al., 1998; Nelson et al., 2002; Weaver \& Flannelly, 2004) and to quality of life in cancer patients, even in the face of high levels of symptoms such as pain and fatigue (Gioiella et al., 1998; Brady et al., 1999).
More recently, spiritual growth and transformation, as a specific dimension associated with spiritual well-being, positive spiritual coping, and intrinsic religiousness, was shown to favor post-traumatic growth in cancer patients (Cole et al., 2008).

In spite of much evidence about the positive role of spirituality in cancer, there is still some controversy. Some studies have found that religion was associated with poor adjustment (Pettet, 1985; Jenkins \& Pargament, 1995) and others do not find any relationship between religiosity and cancer adjustment (Holland et al., 1999; Ritkin et al., 1999).

No data are available about these issues among cancer patients in Southern European countries, in spite of the significant tradition of religion and the role of Catholicism in those countries. The objectives of the present study were to examine: (i) the rate of spirituality/faith and (ii) its effect in molding psychosocial implications in Southern European cancer patients.

\section{METHOD}

\section{Subjects and Procedure}

The data presented here are part of a broader research project involving countries in the Mediterranean area (Southern European Psycho-Oncology Study-SEPOS) and developed to examine the psychosocial problems secondary to cancer, to rate the extent to which such problems are recognized by oncologists, and to develop and implement a training model designed to improve physicians' ability to recognize and detect psychological disorders. The details of the project and its main results are presented elsewhere (Grassi et al., 2004, 2005, 2010; Gil et al., 2005; Travado et al., 2005). In summary, the study was conducted in three countries of the European Union (EU), namely Italy (Hospital S. Anna, Ferrara), Spain (Hospital Duran I Reynalds, Barcelona) and Portugal (Hospital S. José, Lisbon), and in a non-EU country (Switzerland, Lugano Hospital). A convenience sample of outpatients meeting the following criteria was recruited: a diagnosis of cancer between 6 to 18 months, a good performance status (Karnofsky Performance Status $>80$ ), no cognitive deficits or Central Nervous System (CNS) involvement by disease. The study was approved by the ethical committee or related boards of the hospitals and each patient gave his/her written consent to participate. Each patient completed a series of questionnaires and instruments aimed at examining several psychosocial variables.

\section{Measures}

Spirituality, as defined in this study, was measured through a single question "Please rate how much 
your faith (including religiosity) and spiritual values are helping you in coping with your illness." The response was rated on a $0-10$ scale. According to data on VAS instruments (e.g., distress thermometer), scores $\geq 5$ were used as a cut-off score identifying patients supported by their faith and spiritual values. We decided to use such a short instrument for several reasons: the diffusion of single questions/ items to measure psychological variables (e.g., coping, adjustment, depression, distress) with reported good results in terms of sensitivity and specificity; the complexity of multi-item instruments (Peterman et al., 2002; Bussing \& Koenig, 2008), which have not been validated and are not available in the countries where the study has been performed; and the possible role and influence of the cultural background in molding the psychosocial dimension that should be explored in spirituality when applying instruments developed in different cultures.

Anxiety and depression were measured by using the Hospital Anxiety and Depression Scale (HADS) (Zigmond \& Snaith, 1983). According to Carroll et al. (1993), scores between 8 and 10 on anxiety and depression scales indicate "borderline" cases, whereas scores $\geq 11$ identify "clinical" "cases." The cut-off scores of 14 and 19 on the HADS Total were used to evaluate "psychiatric caseness" (Ibbotson et al., 1994) and "severe caseness" (mostly patients with a diagnosis of major depression) (Razavi et al., 1990), respectively.

The National Comprehensive Cancer Network (NCCN) Distress Thermometer (DT) was used to measure the level of emotional distress according to the NCCN guidelines on distress management (NCCN Clinical Practice Guidelines in Oncology ${ }^{\mathrm{TM}}$ Distress Management V.I. 2007). Each patient was asked to answer the question "How distressed have you been today and over the last week?" and to rate on a $0-10$ scale his/her level of distress $(0=$ no distress; $10=$ extreme distress). The DT has been shown to be a reliable instrument in several studies (Jacobsen et al., 2005; Dolbeault et al., 2008; Shim et al., 2008; Grassi et al., 2009, 2010). For the aim of the SEPO study the List of Problems accompanying the DT was not used.

The Mini-Mental Adjustment to Cancer (MiniMAC) scale (Watson et al., 1988, 1994) was used to assess coping to cancer, rating hopelessness, fighting spirit, anxious preoccupation, fatalism, and avoidance. This is a 29-item four-point Likert scale $(1=$ it definitely does nor apply to me; $4=$ it applies to me) yielding five coping strategies, namely, fighting spirit, assessing the tendency to confront and actively face the illness; hopeless-helpless, measuring the tendency to adopt a pessimistic attitude about the illness; anxious preoccupation, which examines the tendency to feel over-worried about the illness; fatalism, which indicates a fatalistic attitude towards the illness; and avoidance, evaluating the active tendency to distract oneself about thought of illness and to avoid confrontation with it. Provisional cut-off scores on anxious preoccupation and hopelessness (mean score $\pm 1 S D$ ) were used to assess maladaptive coping (Watson et al., 1989).

A further Visual Analogue Quality of Life Scale (VAS-QoL) (Grassi et al., 2004) was used to evaluate, on a $0-10$ scale, six further dimensions of qualityof-life, namely, mood, general well-being, physical symptoms (e.g., pain, nausea), leisure activity, adjustment/coping with illness, and perceived social support. Higher scores for the majority of items corresponded to a better condition, except for "physical symptoms" and "coping with illness," where higher scores correspond to worse condition.

A modified version of the Cancer Worries Inventory (CWI) (D'Errico et al., 1999) was used to rate the main preoccupations caused by cancer (e.g., physical and emotional problems, relational worries), which also included three questions on openness, used to rate how open the patient was about his/her illness with the family. Statistical analysis was performed using the SPPS-10 package. Descriptive statistics, ANOVA one-way and Pearson's correlation were used when appropriate.

\section{RESULTS}

\section{Socio-Demographic and Clinical Characteristics}

Three hundred and twenty three patients (Italy, $n=$ 119; Portugal, $n=100$; Spain, $n=68$; Switzerland, $n=36$ ) were recruited. The patients' socio-demographic and clinical characteristics are presented in Table 1. More details about the sample are reported elsewhere (Grassi et al., 2004). In summary, there were 212 women $(69 \%)$ and 95 men $(31 \%)$ (mean age $56.73 \pm 13.3$ ), $41 \%$ were retired, and $72 \%$ of the patients were married. From the clinical point of view, most patients were affected by local or locoregional disease $(83 \%)$ and almost half had breast cancer $(48 \%)$.

\section{Spirituality}

The majority of cancer patients $(79.3 \%)$ referred to being supported by their faith/spirituality throughout their illness, which gave meaning to their existence (VAS-QoL/spirituality $\geq 5$ ). The highest percentage of patients were observed in the Portuguese group (90\%), followed by the Spanish (80.9\%), and the Italian (71.4\%). The lowest percentage was observed in Swiss 
Table 1. Socio-demographic and clinical data for the patients

\begin{tabular}{|c|c|}
\hline \multicolumn{2}{|l|}{ Sex } \\
\hline Male & $99(30.7 \%)$ \\
\hline Female & $224(69.3 \%)$ \\
\hline Age (years) & $56,73 \pm 13,2654$ \\
\hline \multicolumn{2}{|l|}{ Education } \\
\hline No education & $8(2.5 \%)$ \\
\hline$\leq 8$ years & $175(54,2 \%)$ \\
\hline 13 years & $53(16.4 \%)$ \\
\hline$>18$ years & $70(21.7 \%)$ \\
\hline No information & $17(5.3 \%)$ \\
\hline \multicolumn{2}{|l|}{ Marital status } \\
\hline Never married & $35(10.8 \%)$ \\
\hline Separated/divorced & $26(8 \%)$ \\
\hline Married & $233(72.1 \%)$ \\
\hline Windowed & $25(7.7 \%)$ \\
\hline Unknown & $1(0.3 \%)$ \\
\hline \multicolumn{2}{|l|}{ Occupation } \\
\hline Employed & $103(31.9 \%)$ \\
\hline Unemployed & $9(2.8 \%)$ \\
\hline Housewives & $50(15.5 \%)$ \\
\hline Retired & $133(41.2 \%)$ \\
\hline Students & $4(1.2 \%)$ \\
\hline Other & $19(5.9 \%)$ \\
\hline Unknown & $5(1.5 \%)$ \\
\hline \multicolumn{2}{|l|}{ Cancer stage } \\
\hline Local disease & $134(41.5 \%)$ \\
\hline Loco-regional & $87(26.9 \%)$ \\
\hline Metastatic & $55(17.0 \%)$ \\
\hline No information & $47(14.6 \%)$ \\
\hline \multicolumn{2}{|c|}{ Psychological morbidity } \\
\hline Yes & $90(27.9 \%)$ \\
\hline No & $222(68.7 \%)$ \\
\hline No information & $11(3.4 \%)$ \\
\hline
\end{tabular}

patients (66.7\%). These differences were statistically significant between Portuguese and Italian cancer patients $(8.07 \pm 2.45$ versus $6.35 \pm 3.75, p=0.001)$ and between Portuguese and Swiss patients (8.07 \pm 2.45 versus $5.72 \pm 3.03, p=0.002$ ).
The spirituality group of patients had a lower educational level than the non-spirituality group (8.43 \pm 5.35 versus $11.0 \pm 7.34, p=0.001)$. There were no statistically significant differences in the age of patients in the two groups $(57.45 \pm 13.12$ versus $54.38 \pm 13.86, p=0.093$ ), but the spirituality group tended to be older.

\section{Psychological Morbidity and Coping with Cancer}

Spiritual patients reported significantly lower scores than non-spiritual ones on the HADS Total (10.72 \pm 6.91 versus $13.35 \pm 8.93 ; \mathrm{F}=6.33, p=0.012$ ) and on HADS Depression $(4.36 \pm 3.83$ versus $5.90 \pm 4.70$; $\mathrm{F}=7.26, p=0.007$ ). No significant differences were found for the HADS Anxiety. Likewise, patients who had psychological morbidity on the HADS total score ("severe cases" - group 1 - according to the more conservative cut-off $\geq 19$, or "cases" - group 2 - according to the less conservative cut-off $\geq 14$ ) (Razavi et al., 1990; Ibbotson et al., 1994) showed lower scores on the spirituality item than non-cases (group 1: $5.94 \pm 3.57$ versus $7.27 \pm 3.16 ; t=2.65$, $p=0.008$; group 2: $6.19 \pm 3.46$ versus $7.40 \pm 3.12$; $t=2.98, p=0.003$ ).

On the Mini-MAC the spirituality group reported higher scores on "fighting spirit" $(12.77 \pm 2.09$ versus $11.82 \pm 2.29 ; \mathrm{F}=9,68, p=0.002)$, "fatalism" (15.7 \pm 2.80 versus $13.01 \pm 2.49 ; \mathrm{F}=45.42 ; p=0.000)$, and "avoidance" (12.08 \pm 3.36 versus $10.92 \pm 3.25 ; \mathrm{F}=$ $5.80 p=0.017)$. Results are presented in Table 2 .

\section{Quality of Life}

Spiritual patients obtained better scores in terms of $\operatorname{mood}(6.80 \pm 2.40$ versus $5.89 \pm 2.37 ; \mathrm{F}=7.74, p=$ $0.006)$ and leisure activity $(6.72 \pm 2.87$ versus $6.72 \pm 2.74 ; \quad \mathrm{F}=4.11, \quad p=0.44)$. No significant

Table 2. Psychological morbidity and coping with cancer

\begin{tabular}{|c|c|c|c|c|}
\hline & \multirow{2}{*}{$\begin{array}{l}\text { Spirituality group } \\
\text { Mean }(S D)\end{array}$} & \multirow{2}{*}{$\begin{array}{c}\text { Non-spirituality group } \\
\text { Mean }(S D)\end{array}$} & \multicolumn{2}{|c|}{ ANOVA } \\
\hline & & & $\mathrm{F}$ & $p$ \\
\hline \multicolumn{5}{|l|}{ HADS } \\
\hline HADS total & $10.72(6.91)$ & $13.35(8.93)$ & 6.33 & 0.012 \\
\hline HADS depression & $4.36(3.83)$ & $5.90(4.70)$ & 7.26 & 0.007 \\
\hline HADS anxiety & $6.36(3.96)$ & $7.45(5.25)$ & 3.26 & 0.072 \\
\hline \multicolumn{5}{|l|}{ MINI-MAC } \\
\hline Fighting spirit & $12.77(2.09)$ & $11.82(2.29)$ & 9.68 & 0.002 \\
\hline Hopelessness & $14.08(5.92)$ & $12.63(4.93)$ & 3.76 & 0.053 \\
\hline Fatalism & $15.73(2.84)$ & $13.02(2.49)$ & 45.42 & 0.000 \\
\hline Anxious preoccupation & $18.73(5.68)$ & $18.73(6.10)$ & 0.03 & 0.859 \\
\hline Avoidance & $12.08(3.36)$ & $10.92(3.25)$ & 5.80 & 0.017 \\
\hline
\end{tabular}


differences were found for the others dimensions of the VAS-QoL. Results are showed in Table 3.

\section{Concerns about Illness and Openness toward Family}

No differences were found between the two groups in terms of patients' concerns about illness (17.0 \pm $11.56 \pm$ versus $14.58 \pm 10.93 ; \mathrm{F}=.004, p=0.125$ ).

In the same way, there were no relevant differences found between spirituality versus non-spirituality in terms of openness toward the family $(8.44 \pm 2.63$ versus $8.41 \pm 2.27 ; \mathrm{F}=.004, p=0.125)$.

\section{Correlations between the Measures and Predictive Factors}

Significant negative correlations $(p<.01)$ were found between spirituality and education $(r=-.25)$, spirituality and psychological morbidity (HADS total, $r=-0.17$ ), and spirituality and depression $(r=-0.22)$.

Positive significant correlations $(p<0.01)$ were found between spirituality and age, fighting spirit $(r=0.27)$, fatalism $(r=0.50)$, and avoidance $(r=$ $0.23)$ coping styles.

Spirituality was positively correlated with four dimensions of the VAS-QoL, namely mood $(r=0.23$; $p<0.01)$, and well being $(r=0.18 ; p<0.05)$, leisure activity $(r=0.17 ; p<0.05)$, and perceived social support $(r=0.23 ; p<0.05)$.

No significant correlations were found between spirituality and disease stage with the others assessed dimensions.

By conducting regression analysis with spirituality as the dependent variable and the psychosocial

Table 3. Quality of life

\begin{tabular}{|c|c|c|c|c|}
\hline \multirow[b]{2}{*}{ VAS } & \multirow{2}{*}{$\begin{array}{l}\text { Spirituality } \\
\text { group } \\
\text { Mean (DP) }\end{array}$} & \multirow{2}{*}{$\begin{array}{c}\text { Non- } \\
\text { spirituality } \\
\text { group } \\
\text { Mean (DP) }\end{array}$} & \multicolumn{2}{|c|}{ ANOVA } \\
\hline & & & $\mathrm{F}$ & $p$ \\
\hline Mood & $6.80(2.40)$ & $5.897(2.37)$ & 7.74 & 0.006 \\
\hline $\begin{array}{c}\text { General } \\
\text { well- } \\
\text { being }\end{array}$ & $6.61(2.26)$ & $6.08(2.31)$ & 2.79 & 0.095 \\
\hline $\begin{array}{l}\text { Physical } \\
\text { symptoms }\end{array}$ & $4.23(3.03)$ & $4.44(2.89)$ & .269 & 0.604 \\
\hline $\begin{array}{l}\text { Leisure } \\
\text { activity }\end{array}$ & $6.72(2.87)$ & $5.96(2.74)$ & 4.105 & 0.044 \\
\hline $\begin{array}{l}\text { Difficulty in } \\
\text { coping }\end{array}$ & $2.98(3.01)$ & $3.24(3.27)$ & 0.359 & 0.550 \\
\hline Support & $8.68(2.16)$ & $8.09(2.51)$ & 3.675 & 0.056 \\
\hline $\begin{array}{l}\text { Level of } \\
\text { emotional } \\
\text { distress }\end{array}$ & $4.52(3.00)$ & $4.32(2.90)$ & 0.242 & 0.623 \\
\hline
\end{tabular}

variables examined as the independent variables (Mini-MAC subscales, HADS, CWI, Openness, QOL-VAS) the four most potent predictors were fatalism which explained $22 \%$ of the variance, followed by HAD-S depression, which explained a further 3\%, emotional distress $(2 \%)$ and social support (1\%), for a total of $28.4 \%$ of the variance on faith. Results for correlations and multiple regression are presented in Tables 4 and 5.

\section{DISCUSSION}

The purpose of the present study was to examine the relationship between spirituality and psychosocial dimensions among cancer patients of Southern European countries, namely Italy, Portugal, Spain, and Switzerland (Italian speaking area).

A first general result of the study was that the level of spirituality and faith was higher than a cut-off score of 5 in the majority of the sample, confirming the role of these variables in Southern Europe. This was especially true in older patients with a lower level of education. This is in line with similar trends that have been observed in other studies in the same area (Aukst-Margetic et al., 2005; Meraviglia, 2006).

When examining the possible differences among the countries, Portuguese patients seem to be the most religious group, with $90 \%$ referring to being supported by their faith/spirituality in giving meaning to their existence, whereas Swiss patients were the least $(66,7 \%)$. However, this difference may be explained by the socio-demographic characteristics in our samples in which Portuguese patients were significantly older and less educated than Swiss patients (variables that are correlated with spirituality), rather than by cultural differences between countries.

A second, more specific result is related to the overall role of spirituality/faith in the relationship with cancer patients' psychosocial dimensions. Spirituality, particularly, seems to play a protective role towards psychological morbidity, specifically depression, as observed with HADS results. Spiritual patients presented significantly lower levels of psychological morbidity, and reported to be significantly less depressed than non-spiritual patients. These results were also observed in other studies, for instance, mastectomized patients who belonged to the high-religiosity group were significantly less depressed (Aukst-Margetic et al., 2005), and a negative correlation between spirituality (in particular, the existential aspect) and depression was observed in patients with advanced cancer (McCoubrie \& Davies, 2006).

Spirituality seems also to have an important impact on the way a person copes with his/her illness. 
Table 4. Correlations between measures

\begin{tabular}{|c|c|c|c|c|c|}
\hline & Faith and spirituality & Emotional distress & HAD depression & HAD total & Fatalism \\
\hline Age & $0.155^{* *}$ & -0.088 & $0.160(* *)$ & 0.011 & $0.201(* *)$ \\
\hline Education (years) & $-0.213^{* *}$ & -0.023 & -0.079 & -0.076 & $-0.302(* *)$ \\
\hline Stage of cancer & -.103 & 0.032 & 0.099 & 0.016 & -0.020 \\
\hline Faith and spirituality & 1 & 0.029 & $-0.196(* *)$ & $-0.168(* *)$ & $0.475(* *)$ \\
\hline QoL $/ \operatorname{mood}$ & $0.185^{* *}$ & $-0.401(* *)$ & $-0.601(* *)$ & $-0.655(* *)$ & $0.159(* *)$ \\
\hline General well-being & $0.134^{*}$ & $-0.441(* *)$ & $-0.596(* *)$ & $-0.646(* *)$ & $0.128(*)$ \\
\hline Physical symptoms & -0.031 & $0.355(* *)$ & $0.277(* *)$ & $0.319(* *)$ & 0.081 \\
\hline Leisure activity & $.0121 *$ & $-0.395(* *)$ & $-0.518(* *)$ & $-0.542(* *)$ & 0.064 \\
\hline Difficulty in coping & -0.058 & $0.408(* *)$ & $0.465(* *)$ & $0.539(* *)$ & 0.076 \\
\hline Support & $0.132 *$ & $-0.197(* *)$ & $-0.248(* *)$ & $-0.297(* *)$ & 0.063 \\
\hline Level of emotional distress & 0.029 & 1 & $0.405(* *)$ & $0.512(* *)$ & -0.068 \\
\hline HADS anxiety & -0.106 & $0.505(* *)$ & $0.589(* *)$ & $0.897(* *)$ & -0.034 \\
\hline HADS depression & $-0.196 * *$ & $0.405(* *)$ & 1 & $0.886(* *)$ & -0.077 \\
\hline HADS total & $-0.168 * *$ & $0.512(* *)$ & $0.886(* *)$ & 1 & -0.062 \\
\hline Fighting spirit & $0.239 * *$ & -0.061 & $-0.351(* *)$ & $-0.242(* *)$ & $0.376(* *)$ \\
\hline Hopelessness & -0.076 & $0.381(* *)$ & $0.557(* *)$ & $0.603(* *)$ & -0.008 \\
\hline Fatalism & $0.475^{* *}$ & -0.068 & -0.077 & -0.062 & 1 \\
\hline Anxious preoccupation & 0.015 & $0.465(* *)$ & $0.465(* *)$ & $0.611(* *)$ & $0.149(*)$ \\
\hline Avoidance & $0.196 * *$ & 0.054 & -0.051 & 0.028 & $0.377(* *)$ \\
\hline Worries total score & -0.068 & $0.489(* *)$ & $0.499(* *)$ & $0.625(* *)$ & -0.037 \\
\hline
\end{tabular}

${ }^{*} p<0.05 .{ }^{* *} p<0.01$.

We observed that spiritual patients obtained significantly higher scores for "fighting spirit." This active coping style refers to patients having a more positive attitude toward outcome, and taking a more active role in their recovery, than non-spiritual patients. This result appears to be similar to those reported by Weaver \& Flannelly (2004), who found that cancer patients who rely on spiritual and religious beliefs to cope with their illness are more likely to use an active coping style in which they accept and try to deal with their illness in a positive and purposeful way. However spiritual patients were also more fatalistic, which apparently means that they believe that no control can be exerted over the situation. Although these results seem to be contradictory, preliminary studies had already observed this relation between fatalism and spirituality, considering that fatalism might be better construed as a type of acceptance rather than stoic resignation (Cotton et al., 1999). This positive trend and prevalence of fatalism was observed in our previous study in which fatalism was

Table 5. Multiple regression

\begin{tabular}{lcc}
\hline \hline & \multicolumn{2}{c}{ Spirituality } \\
\cline { 2 - 3 } & $p$ & $r^{2}$ \\
\hline Fatalism & 0.000 & 0.222 \\
HADS-D & 0.000 & 0.254 \\
Emotional distress & 0.005 & 0.272 \\
Support & 0.031 & 0.284 \\
& & \\
\hline
\end{tabular}

positively related with fighting spirit and negatively associated with psychosocial morbidity (Grassi et al., 2004). Similarly, in a longitudinal study with Portuguese- treated breast cancer women (Travado \& Matos, 2001) patients who had less psychosocial morbidity had also a more fatalistic coping style.

On the other hand, a positive relation between spirituality and avoidance or denial, was observed, a result that does not converge with literature (Weaver \& Flannelly, 2004; Canada et al., 2006). This may indicate that spiritual patients try to get on with their life without thinking too much about their disease and are more likely to use spiritual or religious rituals (e.g., prayers) as a cognitive distraction (Weaver \& Flannelly, 2004). However, more studies are necessary to test this hypothesis.

Regarding quality of life, there are significant differences between the two groups on some of the dimensions assessed. Spiritual patients have significantly better mood and are more likely to be involved in leisure activities when compared with non-spiritual ones. A positive association was also found between spirituality, general well- being, and support from others. Likewise, in other studies spirituality has been related to quality of life (Brady et al., 1999; Bussing et al., 2005), greater emotional wellbeing, and strengthened emotional support (Mathews et al., 1993).

Results obtained on CWI seem to indicate that there are no differences between spiritual and nonspiritual patients in terms of main preoccupations caused by cancer. This result may suggest that 
spirituality does not influence patients' concerns, despite its relation to how they cope. However, as the patients in our study had an average low score or few concerns and a good performance status, under these circumstances concerns were neither expressive nor discriminative.

Limitations of the study should be mentioned. As it is a quantitative study, and patients' spirituality was assessed by only one VAS item, further studies need to better understand this important dimension among cancer patients living in Southern Europe and belonging to a tradition where the Catholic religion has been for centuries the core of spiritual values and faith. Because in these countries no data have been collected by using any of the several instruments available in the literature, future studies can provide more information about this area. A second limitation has to do with the good performance status criteria and the lower percentage of patients with a metastatic disease in our study. This does not allow us to generalize the results of this study to patients with poorer performance status and in the advanced phase of illness, where the role of spirituality has traditionally been considered extremely important in the relationship with dignity and quality of life (Thompson \& Chochinov, 2008). Third, even if the patients were representative of the four centers and regions where the research was performed, they do not represent the whole cancer population of the four countries. More data are thus needed regarding this aspect.

In summary, our study supports the view that spirituality is an important component of the healing process that should be assessed and valued in integrated cancer care (Fitchett \& Handzo, 1998; Musick et al., 1998; Breitbart, 2002; Torosian \& Biddle, 2005). The role of support related to the patients' faith in giving meaning to their existence and their spirituality is an important protective factor for facilitating their adaptation to cancer. Further research is needed in the specific cultural area of Southern Europe.

\section{ACKNOWLEDGMENTS}

The study, as part of a larger project ("Improving health staff's communication and assessment skills of psychosocial morbidity and quality of life in cancer patients: A study in Southern European countries"), has been funded by the European Community (Agreement SI2.307317 2000CVGG2-026 - between the European Commission Health and Consumer Protection-Commission on Cancer and the University of Ferrara) and coordinated by L. Grassi, University of Ferrara, Italy. The research group thanks all the colleagues and patients participating in the study.

In the SEPOS project "Improving health staff's communication and assessment skills of psychosocial morbidity and quality of life in cancer patients: a study in
Southern European countries" (Principal Investigator Luigi Grassi, M.D.), the following persons participated in different ways: Sónia Cunha(1); Rute Pires(1); Hugo Lucas(1); Maria Francisca Hollenstein(2), Jorge Maté(2); Katia Magnani(2); Silvana Sabato(3); Elena Rossi(3); Giulia Tralli(3); and Michele Tomamichel from Lugano Hospital, Switzerland.

\section{REFERENCES}

Aukst-Margetić, B., Jakovljević, M., Margetic, B., et al. (2005). Religiosity, depression and pain in patients with breast cancer. General Hospital Psychiatry, 27, 250-255.

Brady, M.J., Peterman, A.H., Fitchett, G., et al. (1999). A case for including spirituality in quality of life measurement in oncology. Psycho-oncology, 8, 417-428.

Breitbart, W. (2002). Spirituality and meaning in supportive care: Spirituality- and meaning-centered group psychotherapy interventions in advanced cancer. Supportive Care in Cancer, 10, 272-280.

Broyles, P.A. \& Drenovsky, C.K. (1992). Religious attendance and the subjective health in the elderly. Review of Religious Research, 34, 152-160.

Bussing, A., Ostermann, T. \& Matthiessen, P.F. (2005). Search for meaningful support and the meaning of illness in German cancer patients. Anticancer Research, 25, 1449-1455.

Bussing, A. \& Koenig, H.G. (2008). The benefit through spirituality/religiosity scale - a 6-item Measure for use in health outcome studies. International Journal of Psychiatry and Medicine, 38, 493-506.

Canada, A.L., Parker, P.A., de Moor, J.S., et al. (2006). Active coping mediates the association between religion/ spirituality and quality of life in ovarian cancer. Gynecologic Oncology, 101, 102-107.

Carroll, B.T., Kathol, R.G., Noyes, R., et al. (1993). Screening for depression and anxiety in cancer patients using the Hospital Anxiety and Depression Scale. General Hospital Psychiatry, 15, 69-74.

Cole, B.S., Hopkins, C.M., Tisak, J., et al. (2008). Assessing spiritual growth and spiritual decline following a diagnosis of cancer: Reliability and validity of the spiritual transformation scale. Psycho-Oncology, 17, 112-121.

Cotton, S.P., Levine, E.G., Fitzpatrick, C.M., et al. (1999). Exploring the relationships among spiritual wellbeing, quality of life and psychological adjustment in women with breast cancer. Psycho-Oncology, 8, 429-438.

D’Errico, G.M., Galassi, J.P., Schanberg, R., et al. (1999). Development and validation of the Cancer Worries Inventory: A measure of illness-related cognitions. Journal of Psychosocial Oncology, 17, 119-137.

Dolbeault, S., Bredart, A., Mignot, V., et al. (2008). Screening for psychological distress in two French cancer centers: Feasibility and performance of the adapted distress thermometer. Palliative Supportive Care, 6, $107-117$.

Elkins, D.N., Hedstrom, L.J., Hughes, L.L., et al. (1988). Toward a humanistic phenomenological spirituality. Journal of Humanist Psychology, 28, 5-18.

Ellison, C.G. (1991). Religious involvement and subjective well-being. Journal of Health and Social Behavior, 32, $80-99$. 
Feher, S. \& Maly, R.C. (1999). Coping with breast cancer in later life: The role of religious faith. Psycho-Oncology, 8 , 408-416.

Fitchett, G., Peterman, A.H. \& Cella, D. (1996). Spiritual beliefs and quality of life in cancer and HIV patients. Psycho-Oncology, 5, Supplement 3.

Fitchett, G. \& Handzo, G. (1998). Spiritual assessment, screening and intervention. In Psycho-Oncology, Holland, J.C. (ed.), pp. 790-808. New York: Oxford University Press.

Gil, F., Grassi, L., Travado, L., et al. (2005) Use of AVisual Analogue Scale to measure psychosocial concomitants of cancer in Southern European countries. Supportive Care in Cancer, 13, 600-606.

Gioiella, M.E., Berkman, B. \& Robinson, M. (1998). Spirituality and quality of life in gynecologic oncology patients. Cancer Practice, 6, 333-338.

Grassi, L., Travado, L., Gil, F., et al. (2004). Psychosocial morbidity and its correlates in cancer patients of the Mediterranean area: Findings from the Southern European Psycho-Oncology Study (SEPOS). Journal of Affective Disorders, 83, 243-248.

Grassi, L., Travado, L., Gil, F., et al. (2005). A communication intervention for training Southern European oncologists to recognize psychosocial morbidity in cancer patients. I - Development of the model and preliminary results on physicians' satisfaction. Journal of Cancer Education, 20, 79-84.

Grassi, L., Sabato, S., Rossi, E., et al. (2009). Affective syndromes and their screening in cancer patients with early and stable disease: Italian ICD-10 data and performance of the Distress Thermometer from the Southern European Psycho-Oncology Study (SEPOS). Journal of Affective Disorders, 114, 193-199.

Grassi, L., Travado, L., Gil, F., et al. (2010). Hopelessness and related variables among cancer patients in the Southern European Psycho-Oncology Study (SEPOS). Psychosomatics, 51, 201-207.

Hiatt, J.F. (1986). Spirituality, medicine and healing. Southern Medical Journal, 79, 736-743.

Holland, J.C., Passik, S., Kash, K.M., et al. (1999). The role of religious and spiritual beliefs in coping with melanoma. Psycho-Oncology, 8, 14-26.

Ibbotson, T., Maguire, P., Selby, P., et al. (1994). Screening for anxiety and depression in cancer patients: The effects of disease and treatment. European Journal of Cancer, 30, 37-40.

Idler, E.L. (1987). Religious involvement and the health of the elderly: Some hypotheses and an initial test. Social Forces, 66, 226-238.

Jacobsen, P.B., Donovan, K.A., Trask, P.C., et al. (2005). Screening for psychologic distress in ambulatory cancer patients. Cancer, 103, 1494-1502.

Jenkins, R.A. \& Pargament, K.I. (1995). Religion and spirituality as resources for coping with cancer. Journal of Psychosocial Oncology, 13, 51-74.

Larson, D.B. \& Greenwold-Milano, M.A. (1995). Are religion and spirituality clinically relevant in health care? Mind-Body Medicine, 1, 147-157

Ley, D.C.H. \& Corless, I.B. (1988). Spirituality and hospice care. Death Studies, 12, 101-110.

Matthews, D.A., Larson, D.B. \& Barry, C.P. (1993). The Faith Factor: An Annotated Bibliography of Clinical Research on Spiritual Subjects, Vol.1. Rockville: National Institute for Healthcare Research.

Matthews, D.A. \& Larson, D.B. (1995). The Faith Factor: An Annotated Bibliography of Clinical Research on
Spiritual Subjects, Vol. 3. Rockville: National Institute for Healthcare Research.

Matthews, D.A. (1997). Religion and spirituality in primary care. Mind-Body Medicine, 2, 9-19.

McCoubrie, R.C. \& Davies, A.N. (2006). Is there a correlation between spirituality and anxiety and depression in patients with advanced cancer? Supportive Care in Cancer, 4, 379-385.

McCullough, M.E., Hoyt, W.T., Larson, D.B., et al. (2000). Religious involvement and mortality: A meta-analytic review. Health Psychology, 19, 211-222.

Meraviglia, M. (2006). Effects of spirituality in breast cancer survivors. Oncology Nursing Forum, 33, E1-7. http://ons.metapress.com/content/

Moberg, D.O. (1979). Development of social indicators of spiritual well-being for quality of life research. In Spiritual Well-Being: Sociological Perspectives, Moberg, D.O. (ed.), pp. 1-13. Washington, DC: University Press of America.

Musick, M.A., Koenig, H.G., Larson, D.B., et al. (1998). Religion and Spiritual Beliefs. In Psycho-Oncology, Holland, JC (ed.), pp. 780-789. New York: Oxford University Press.

Mytko, J.J. \& Knight, S.J. (1999). Body, mind and spirit: Towards the integration of religiosity and spirituality in cancer quality of life research. Psycho-Oncology, 8, $439-450$

National Comprehensive Cancer Network. (2007). Clinical practice guidelines in oncology (NCCN Guidelines ${ }^{\mathrm{TM}}$ ). Distress management V.I. 2007/2008. http://www. nccn.org.

Nelson, C.J., Rosenfeld, J.B., Breitbart, W., et al. (2002). Spirituality, religion, and depression in the terminally ill. Psychosomatics, 43, 213-220.

Peterman, A.H., Fitchett, G., Brady, M.J., et al. (2002). Measuring spiritual well-being in people with cancer: The functional assessment of chronic illness therapyspiritual well-being scale (FACIT-Sp). Annals of Behavioral Medicine, 24, 49-58.

Pettet, J.R. (1985). Religious issues presented by cancer patients seen in psychiatric consultation. Journal of Psychosocial Oncology, 3, 53-66.

Razavi, D., Delvaux, N., Farvacques, C., et al. (1990). Screening for adjustment disorders and major depressive disorders in cancer in-patients. British Journal of Psychiatry, 156, 79-83.

Reed, P.G. (1987). Spirituality and well-being in terminally ill hospitalized adults. Research in Nursing and Health, 10, 335-344.

Ritkin, A., Daddi, S., Karagji, B., et al. (1999). Religious and other predictors of psychosocial adjustment in cancer patients. Psychosomatics, 40, 251-256.

Shim, E.J., Shin, Y.W., Jeon, H.J., et al. (2008). Distress and its correlates in Korean cancer patients: Pilot use of the distress thermometer and the problem list. PsychoOncology, 17, 548-555.

Smith, T.B., McCullough, M.E. \& Poll, J. (2003). Religiousness and depression: Evidence for a main effect and the moderating influence of stressful life events. Psychological Bulletin, 129, 614-636.

St. George, A. \& McNamara, P.H. (1984). Religion, race and psychological well-being. Journal for the Scientific Study of Religion, 23, 351-363.

Thompson, G.N. \& Chochinov, H.M. (2008). Dignitybased approaches in the care of terminally ill patients. Current Opinion in Supportive and Palliative Care, 2, 49-53. 
Thune-Boyle, I.C., Stygall, J.A., Keshtgar, M.R., et al. (2006). Do religious/spiritual coping strategies affect illness adjustment in patients with cancer? A systematic review of the literature. Social Science and Medicine, $63,151-164$.

Torosian, M.H. \& Biddle, V.R. (2005). Spirituality and healing. Seminars in Oncology, 32, 232-236.

Travado, L. \& Matos, J.N. (2001). Who lives longer and better? A study with treated breast cancer women. Liberdade, Anais Científicos da Universidade Independente, 2, 145-153.

Travado, L., Grassi, L., Gil, F., et al. (2005). Physicianpatient communication among Southern European cancer physicians: The influence of psychosocial orientation, and burnout. Psycho-Oncology, 14, 661-670.
Watson, M., Greer, S., Young, J., et al. (1988). Development of a questionnaire measure of adjustment to cancer: The MAC scale. Psychological Medicine, 18, 203-209.

Watson, M., Greer, S., \& Bliss, J.M. (1989). Mental Adjustment to Cancer (MAC) Scale Users' Manual. Sutton, Surrey: Cancer Research Campaign Medical Research Group, Royal Marsden Hospital.

Weaver, A.J. \& Flannelly, K.J. (2004). The role of religion/ spirituality for cancer patients and their caregivers. Southern Medical Journal, 97, 1210-1214.

Williams, D.R., Larson, D.B., Buckler, R.E., et al. (1991). Religion and psychological distress in a community sample. Social Science in Medicine, 32, 1257-1262.

Zigmond, S.A. \& Snaith, R.P. (1983). The Hospital Anxiety and Depression Scale. Acta Psychiatrica Scandinavica, $67,361-370$. 